\title{
Laparoscopic Common Bile Duct Exploration : A Feasible Option for Choledocholithiasis in Patients with Previous Gastrectomy
}

\author{
Hye Ryeon Choi, M.D., Joo Dong Kim, M.D., Dong Lak Choi, M.D. \\ Division of Hepatobiliary Pancreas Surgery and Abdominal Organ Transplantation, Department of Surgery, Catholic University of Daegu College of Medicine, \\ Daegu, Korea
}

Purpose: Previous gastrectomy has been considered to be a relative contraindication for laparoscopic common bile duct exploration (LCBDE) because of concerns regarding severe adhesions in the operative field and technical complexity. This study evaluated the feasibility and safety of LCBDE in patients with previous gastrectomy.

Methods: We retrospectively reviewed the clinical outcomes of 58 patients who underwent LCBDE in our institution between January 2005 and December 2014: group I comprised patients with no previous abdominal surgery $(n=43)$ and group II comprised patients with previous gastrectomy $(n=15)$. Patient demographics and perioperative variables were compared between groups.

Results: The perioperative variables did not differ significantly between groups. The operating time, open conversion rate, and morbidity rate were similar in groups I and II, despite the more complicated cases in group II. Moreover, the presence of remnant bile duct stones and biliary strictures, and the postoperative hospital stay, did not differ significantly between groups. The mean time to oral intake did not differ between groups, although this diet resumption time was significantly shorter in groups I and II than in a group undergoing open choledocholithomy ( $p=0.04)$.

Conclusion: Laparoscopic common bile duct exploration is safe and effective in patients with histories of gastrectomy.

Keywords: Laparoscopy, Gastrectomy, Choledocholithiasis, Complication

This is an Open Access article distributed under the terms of the Creative Commons Attribution Non-Commercial License (http:// creativecommons.org/licenses/by-nc/4.0/) which permits unrestricted non-commercial use, distribution, and reproduction in any medium, provided the original work is properly cited.
Received June 10, 2016

Revised September 14, 2016

Accepted October 7, 2016

Corresponding author Joo Dong Kim

Division of Hepatobiliary Pancreas Surgery and Abdominal Organ Transplantation, Department of Surgery, Catholic University of Daegu College of Medicine, 33, Duryugongwon-ro 17-gil, Nam-gu, Daegu 42472, Korea Tel: +82-53-650-3074 Fax: +82-53-650-4950 E-mail:milledr@cu.ac.kr

Copyright (C) 2016 The Journal of Minimally Invasive Surgery. All rights reserved.

\section{INTRODUCTION}

Laparoscopic cholecystectomy (LC) leads to more rapid postoperative recovery and more acceptable cosmetic outcomes than does open cholecystectomy. ${ }^{1,2}$ Consequently, LC has replaced open cholecystectomy as the standard procedure for benign gallbladder (GB) disease. ${ }^{1-3}$ With the rapid development of LC, less invasive procedures have replaced traditional open common bile duct (CBD) exploration. ${ }^{4-6}$ The mainstream minimally invasive treatment for concomitant $\mathrm{CBD}$ and $\mathrm{GB}$ stones is endoscopic retrograde cholangiopancreatography (ERCP), with endoscopic stone extraction combined with LC. However, this treatment requires a two-stage approach and can lead to patient discomfort and ERCP-related complications, such as bleeding, perforation, and pancreatitis. ${ }^{5,8}$

Laparoscopic common bile duct exploration (LCBDE) was introduced in 1991, and has been proven to be a safe, effective method for treating concomitant gallstones and CBD stones in a single-stage approach. ${ }^{1,56}$ This procedure results in shorter hospital stays and has a similar stone clearance rate and cost 
effectiveness, with fewer ERCP-related complications., ${ }^{9}$ Despite the dramatic results of endoscopic and laparoscopic approaches to CBD stones, previous gastrectomy has posed a major challenge for both procedures due to the altered upper gastrointestinal anatomy and adhesion. ${ }^{6}$ The overall success rate of ERCP ranges from $42 \%$ to $92 \%$, and difficulty is encountered in approaching the papilla and achieving correct cannulation and sphicterotomy, ${ }^{6,11}$ Similarly, LCBDE in these situations is challenging because of extensive adhesions and altered gastrointestinal anatomy, which may increase the technical difficulty and risk of organ injury. ${ }^{1,5,6}$ Therefore, most surgeons prefer open exploration of the CBD immediately after a failed endoscopic attempt. ${ }^{6}$

Nevertheless, with the development of surgical skills and instruments, LC has been performed recently in cases complicated by previous gastrectomy. ${ }^{3-5}$ However, few verified trials of a laparoscopic approach for CBD stones in the context of previous gastrectomy have been reported. Therefore, this study evaluated the feasibility and safety of LCBDE in patients with previous gastrectomy.

\section{MATERIALS AND METHODS}

Between January 2005 and December 2014, 58 patients with CBD stones underwent $\mathrm{LCBDE}$ at our institution. The 58 patients were divided into two groups: those without ( $n=43$, group I) and with ( $n=15$, group II) previous gastrectomy. Group I included patients with no previous abdominal surgery $(n=36)$ and those who had previously undergone abdominal operations that would not affect this laparoscopic procedure, such as appendectomy or hysterectomy $(n=7)$.

Diagnosis of CBD stones was based on abdominal computed tomography, received ERCP, or magnetic resonance cholangiopancreaticography (MRCP) in cases with failed ERCP with liver function test results.

LCBDE has been applied to the patients with failed ERCP in our institution: incomplete stone removal, failed cannulation, or altered anatomy related to gastric resection. We tried ERCP as a first modality in patients with distal gastrectomy regardless of anastomosis method but it was not performed in patients with previous total gastrectomy due to acute angulation in anastomosis area.

Medical records were reviewed retrospectively and the two groups were compared in terms of patient demographics and intra- and postoperative findings. The study protocol was approved by the institutional review board of the Daegu Catholic University Medical Center.

\section{Surgical techniques}

The surgical technique used for LCBDE at our institution has been described in detail elsewhere. ${ }^{4-6}$

Under general anesthesia, the patient is positioned supine. A $10-\mathrm{mm}$ trocar is used in the subumbilical area as a camera port, a $5-\mathrm{mm}$ trocar is placed in the epigastric area, a $10-\mathrm{mm}$ trocar is used in the right upper abdomen, and an additional $5-\mathrm{mm}$ trocar is placed in the right subcostal area if necessary. After cholecystectomy, careful dissection is performed to identify the anterior surface of the CBD, where a longitudinal choledochotomy is performed. After the removal of any stones with a stone basket, stone forceps, saline flushing, or balloon catheter, a choledochoscope is used to find residual stones in the intrahepatic duct and CBD. A T-tube is inserted at the surgeon's discretion in the setting of residual stones or according to the state of the CBD. In post-gastrectomy patients, the first trocar is usually inserted using the open technique at a site far from the previous incision.

\section{Statistical analysis}

All numerical data are reported as means with standard deviations or as medians with ranges. Student's t-test or the Mann-Whitney $U$-test was used to compare continuous variables, depending on their distributions. The chi-squared or Fisher's exact test was used to compare categorical variables after verifying certain assumptions. All analyses were performed using IBM SPSS Statistics ver. 19.0 (IBM, Armonk, NY, USA). $p$ values $<0.05$ were considered to be significant.

\section{RESULTS}

The study enrolled 31 (53.4\%) men and 27 (46.6\%) women with a mean age of $64.5 \pm 14.7$ (range 29 92) years. Gastrectomy had been performed due to gastric cancer in $73.3 \%$ of 15 patients. The type of gastrectomy were distal gastrectomy with Billoth I anastomosis in 2 patients, distal gastrectomy with Billoth II anastomosis in 6, and total gastrectomy in 7. All patients with previous distal gastrectomy $(n=8)$ received LCBDE due to failed ERCP: failed cannulation $(n=6)$, incomplete stone removal $(n=1)$, and failed endoscopy entry due to acute angulation $(n=1)$.

The clinical outcomes are shown in Table 1. In three (5.2\%) patients, procedures were converted to open surgery due to extensive adhesions or severe fibrosis at the porta hepatis; the rate of conversion did not differ significantly between groups ( $4.7 \%$ vs. $6.7 \% ; p=0.762$ ). Remnant stones were found in three (5.2\%) patients, with no significant difference between groups (7.0\% vs. $0.0 \%, p=0.293$ ). All retained bile duct stones were re- 
Table 1. The perioperative clinical outcomes between two groups

\begin{tabular}{|c|c|c|c|c|}
\hline & & $\begin{array}{c}\text { Group I* } \\
\mathrm{N}=43\end{array}$ & $\begin{array}{c}\text { Group } I^{\dagger} \\
N=15\end{array}$ & $p$ value \\
\hline Age (year) & Mean \pm SD & $63.2 \pm 15.7$ & $66.5 \pm 9.5$ & 0.333 \\
\hline Gender & $M: F$ & 22:21 & 9:6 & 0.555 \\
\hline Operation time (minute) & Mean $\pm S D$ & $124.4 \pm 42.6$ & $126.6 \pm 35.6$ & 0.756 \\
\hline Open conversion $(\%)$ & & $2(4.7)$ & $1(6.7)$ & 0.762 \\
\hline Postoperative hospital stay (day) & Mean $\pm S D$ & $9.4 \pm 4.9$ & $10.3 \pm 5.1$ & 0.538 \\
\hline Diet resumption (day) & Mean $\pm S D$ & $2.4 \pm 1.2$ & $2.3 \pm 1.3$ & 0.890 \\
\hline T-tube insertion (\%) & & $10(23.3)$ & $1(6.7)$ & 0.158 \\
\hline
\end{tabular}

${ }^{*}$ Group I = Patients without a history of previous abdominal surgery; ${ }^{\dagger}$ Group II = Patients with a history of previous gastrectomy.

Table 2. The comparison for postoperative complications between the two groups

\begin{tabular}{|c|c|c|c|}
\hline & $\begin{array}{c}\text { Group I* } \\
N=43\end{array}$ & $\begin{array}{c}\text { Group } I^{\dagger} \\
N=15\end{array}$ & $p$ value \\
\hline Bile leakage $(\%)$ & 1 (2.3) & $0(0.0)$ & 0.551 \\
\hline Biliary stricture $(\%)$ & $0(0.0)$ & $0(0.0)$ & $N A^{\ddagger}$ \\
\hline Wound infection $(\%)$ & $6(14.0)$ & $3(20.0)$ & 0.578 \\
\hline Postoperative bleeding $(\%)$ & $1(2.3)$ & $0(0.0)$ & 0.551 \\
\hline Remnant CBD ${ }^{\S}$ stones $(\%)$ & $3(7.0)$ & $0(0.0)$ & 0.293 \\
\hline
\end{tabular}

${ }^{*}$ Group I = Patients without a history of previous abdominal surgery; ${ }^{\dagger}$ Group II = Patients with a history of previous gastrectomy; ${ }^{\ddagger} \mathrm{NA}=$ Not applicable; ${ }^{\text {₹}} \mathrm{CBD}=$ Common bile duct.

moved by ERCP or percutaneous transhepatic biliary drainage (PTBD). The mean operation time did not differ significantly between groups, despite the more complex procedures and additional adhesiolysis required in group II (124.4 \pm 42.6 vs. 126.6 \pm 35.6 minutes, $p=0.756$ ). After the CBD exploration was performed, T-tube drain was used in 11 patients (18.9\%) and primary closure was done in 47 patients (81.1\%) but the incidence of T-tube insertion between two groups was not significantly different (23.3\% vs. 6.7\%; $p=0.158$ ).

The postoperative courses are summarized at Table 2. Postoperative complications occurred in 11 (19.0\%) of the 58 patients. The most common postoperative complication was wound infection $(n=9,15.5 \%)$. The incidence of postoperative complications was not significantly higher in group II than in group I (20\% vs. $18.6 \% ; p=0.906)$. Bile leakage occurred only in one (1.7\%) patient, and this complication was not related to T-tube insertion.

The time until diet resumption did not differ between groups (2.4 \pm 1.2 vs. $2.3 \pm 1.3$ days, $p=0.890)$. However, the diet resumption time was significantly shorter in groups I and II than in a group of patients who underwent open choledocholithomy ( $p=0.04)$.

\section{DISCUSSION}

With the development of skills and devices for laparoscopic procedures, LC has become the gold standard for treating gallstones, replacing traditional open CBD exploration. ${ }^{4.5}$ These new procedures are ERCP with or without endoscopic sphincterotomy (EST), LCBDE, and radiological intervention. ${ }^{5}$ ERCP followed by LC has been accepted for patients with concomitant $\mathrm{GB}$ and $\mathrm{CBD}$ stones in most centers, but the optimal treatment for these conditions remains controversial. ${ }^{4.5}$ Several studies have reported on the efficacy, safety, and efficiency of CBD stone removal by ERCP or LCBDE. ${ }^{4}$ In a prospective randomized trial that included 122 patients, Rogers et al. ${ }^{12}$ compared LCBDE and ERCP, and concluded that both procedures have equal efficacy in terms of ductal stone clearance, as well as similar morbidity rates. Both groups had similar patient acceptance rates and quality of life scores. ERCP has potentially serious complications, such as pancreatitis, cholangitis, duodenal perforation, and life-threatening hemorrhage., ${ }^{5,13}$ The major advantage of LCBDE is that it enables concomitant $\mathrm{GB}$ and $\mathrm{CBD}$ stone removal while preserving the function of the sphincter of Oddi, which avoids ERCP-related complications and post-procedural pain. ${ }^{4.5}$ Furthermore, CBD stones cannot be managed with ERCP in many cases, including in patients with impacted stones, histories of gastrectomy, and periampullary diverticulum. ${ }^{1415}$ LCBDE is the best alternative to failed ERCP for these difficult choledocholithiasis cases.

Initially, previous abdominal surgery, especially gastrectomy, was considered to be a relative contraindication to $\mathrm{LC}$ or LCBDE. Previous gastrectomy was considered to pose a problem when performing LC due to the dense adhesions in- 
volving the hepatoduodenal ligament and upward adhesion of the second portion of the duodenum, as reflected in the longer operating times and higher conversion rates in previous gastrectomy groups. ${ }^{16,17}$ The most common approach to operative lithotripsy in patients with previous gastrectomy continues to be open exploration, despite the impressive results obtained with LCBDE in the last decade and the favorable postoperative outcomes as compared with a two-stage approach for uncomplicated cases of CBD stones. ${ }^{6}$

With the development of surgical skills and instruments and the accumulated experience of laparoscopic surgeons, complicated laparoscopic procedures can be performed even in patients who have undergone previous operations. ${ }^{5}$ Surgeons may hesitate to take a laparoscopic approach for CBD stones in patients with previous gastrectomy in the presence of (1) possible risk of injury to organs adjacent to the previous incision wound during insertion of the Veress needle or trocar; (2) severe curtain-like adhesion from the previous operation that prevents access to the target organ, despite the minimal establishment of pneumoperitoneum; or (3) risk of bowel injury during adhesiolysis. ${ }^{4,5}$

These problems can be overcome. First, the first trocar port should be located far from the previous incision, and open insertion (Hasson technique) is definitely much safer. We recommend peritoneal access using the open technique in patients with previous upper abdominal operations. Second, laparoscopic adhesiolysis can be performed safely under a magnified view to help avoid inadvertent visceral injury. Third, the operative view can be optimized by inserting the laparoscope through different trocar ports. Finally, electrocautery should not be used when the dissection is close to the bowel, to prevent inadvertent burn injury. ${ }^{5,6}$ In fact, the operating time and complication rates in the previous gastrectomy group did not differ from those in the control group once our surgeons became skilled with these techniques.

T-tube insertion remains problematic, and primary closure of the bile duct after exploration with or without a biliary stent is currently in vogue. ${ }^{5}$ Traditionally, T-tube insertion after exploration is advisable in cases in which the endoscopic approach fails. ${ }^{13}$ The T-tube can serve as a safety valve in cases with access difficulty to allow subsequent stone removal and stricture dilatation. ${ }^{6.18}$ However, many studies have reported 10.5 20\% complication rates, such as bile leakage, local pain, and patient inconvenience, related to T-tube usage. ${ }^{19,20}$ More- $^{-}$ over, several studies have reported that T-tube drainage does not prevent the recurrence of ductal stones or biliary stricture. ${ }^{21}$ We also showed that T-tube drainage was not related to stone recurrence, and no biliary stricture occurred in the Ttube or primary closure group during follow-up.

In conclusion, the postoperative findings following LCBDE in patients with previous gastrectomy were comparable to those for patients with no such history in terms of operating time, conversion rate, and complication rate. Therefore, LCBDE is a safe, effective treatment modality in patients with histories of gastrectomy, as long as the principle of adhesiolysis is followed.

\section{REFERENCES}

1) Kwon AH, Inui H, Imamura A, Kaibori M, Kamiyama Y. Laparoscopic cholecystectomy and choledocholithotomy in patients with a previous gastrectomy. J Am Coll Surg 2001;193:614-619.

2) Sasaki A, Nakajima J, Nitta H, Obuchi T, Baba S, Wakabayashi G. Laparoscopic cholecystectomy in patients with a history of gastrectomy. Surg Today 2008;38:790-794.

3) Schirmer BD, Edge SB, Dix J, Hyser MJ, Hanks JB, Jones RS. Laparoscopic cholecystectomy. Treatment of choice for symptomatic cholelithiasis. Ann Surg 1991;213:665-676; discussion 677.

4) Lee HM, Min SK, Lee HK. Long-term results of laparoscopic common bile duct exploration by choledochotomy for choledocholithiasis: 15-year experience from a single center. Ann Surg Treat Res 2014;86:1-6.

5) Yun KW, Ahn YJ, Lee HW, et al. Laparoscopic common bile duct exploration in patients with previous upper abdominal operations. Korean J Hepatobiliary Pancreat Surg 2012;16:154-159.

6) Tang CN, Tsui KK, Yang GP, Ha JP, Li MK. Laparoscopic exploration of common bile duct in post-gastrectomy patients. Hepatogastroenterology 2008;55:846-849.

7) Soper NJ. Laparoscopic general surgery--past, present, and future. Surgery 1993;113:1-3.

8) Wang P, Li ZS, Liu F, et al. Risk factors for ERCP-related complications: a prospective multicenter study. Am J Gastroenterol 2009;104:31-40.

9) Vandervoort J, Soetikno RM, Tham TC, et al. Risk factors for complications after performance of ERCP. Gastrointest Endosc 2002;56:652-656.

10) Poulose BK, Arbogast PG, Holzman MD. National analysis of inhospital resource utilization in choledocholithiasis management using propensity scores. Surg Endosc 2006;20:186-190.

11) Faylona JM, Qadir A, Chan AC, Lau JY, Chung SC. Small-bowel perforations related to endoscopic retrograde cholangiopancreatography (ERCP) in patients with Billroth II gastrectomy. Endoscopy 1999;31:546-549.

12) Rogers SJ, Cello JP, Horn JK, et al. Prospective randomized trial of LC+LCBDE vs ERCP/S+LC for common bile duct stone disease. Arch Surg 2010;145:28-33.

13) Tai CK, Tang CN, Ha JP, Chau CH, Siu WT, Li MK. Laparoscopic exploration of common bile duct in difficult choledocholithiasis. Surg Endosc 2004;18:910-914.

14) Frazee RC, Roberts JW, Symmonds R, et al. What are the con- 
traindications for laparoscopic cholecystectomy? Am J Surg 1992;164:491-494; discussion 494-495.

15) Hanney RM, Carmalt HL, Merrett N, Tait N. Vascular injuries during laparoscopy associated with the Hasson technique. J Am Coll Surg 1999;188:337-338.

16) Karayiannakis AJ, Polychronidis A, Perente S, Botaitis S, Simopoulos C. Laparoscopic cholecystectomy in patients with previous upper or lower abdominal surgery. Surg Endosc 2004;18:97-101.

17) Jorgensen JO, Hunt DR. Laparoscopic cholecystectomy. A prospective analysis of the potential causes of failure. Surg Laparosc Endosc 1993;3:49-53.

18) Gamal EM, Szabo A, Szule E, et al. Percutaneous video choledo- choscopic treatment of retained biliary stones via dilated $\mathrm{T}$-tube tract. Surg Endosc 2001;15:473-476.

19) Seale AK, Ledet WP, Jr. Primary common bile duct closure. Arch Surg 1999;134:22-24.

20) Sorensen VJ, Buck JR, Chung SK, Fath JJ, Horst HM, Obeid FN. Primary common bile duct closure following exploration: an effective alternative to routine biliary drainage. Am Surg 1994;60:451-454.

21) Uchiyama $K$, Onishi $H$, Tani $M$, et al. Long-term prognosis after treatment of patients with choledocholithiasis. Ann Surg 2003;238:97-102. 